\title{
O Selo Casa Azul como política urbana de incentivo à habitação sustentável e sua relação com o direito à cidade
}

The "Selo Casa Azul" as urban politics to incentive sustainable housing and its relation with the right to the city

El "Selo Casa Azul" como política urbana de incentivar la vivienda sostenible y su relación con el derecho a la ciudad

Daniele da Conceição Matos Alves

Advogada, mestranda Direitos Fundamentais, UNAMA, Brasil conceicaoalvesadvocacia@gmail.com

Gustavo Carvalho de Freitas

Advogado, Esp. Direito Imobiliário e Direito Constitucional gustavocarvadvogado@bol.com.br

\section{Jorge Luiz Oliveira dos Santos}

Dr. Ciências Sociais (Antropologia), Prof. Pós-Stricto Senso I, UNAMA, Brasil jorgeluiz_dossantos@hotmail.com 

Uma das razões para essa situação é apontada por David Harvey ${ }^{8}$ como sendo a hegemonia do capitalismo, com a preponderância dos conceitos individualistas em nossa sociedade, a qual está entrando, porém, em momento de soerguimento dos direitos humanos, os quais se relacionam com o Direito à Cidade, definido como um direito coletivo diretamente relacionado ao tipo de pessoas que se quer na sociedade e qual futuro se almeja construir.

O mesmo autor também define o Direito à Cidade como algo que ultrapassa a garantia individual, ele é coletivo e se reinventa continuamente. Inclusive na observância do processo histórico, é possível notar os ajustes e adaptações que, até então sempre se deram para atender ao capital.

Conforme se verá no estudo da certificação, a orientação para ocupação de áreas já estruturadas é um dos pilares de implantação do Projeto. Assim como outras ações que devem evitar que as massas urbanas estejam excluídas do Direito à Cidade.

Também tratando dos problemas urbanos, Henri Lefebvre os relaciona como o processo de industrialização, afirmando que a cidade é um "objeto espacial" 9 a ser estudado sob diferentes enfoques como o econômico e o político. Além disso, afirma ainda que o Direito à Cidade não é algo simplesmente instituído, mas modelado e apropriado, e tudo ocorrendo de forma simultânea.

Contemporaneamente, falar em Direito à Cidade, propõe, conjuntamente, a busca de soluções sustentáveis. Uma delas, conforme Jaqueline Rego ${ }^{10}$, é o incentivo a cidades mais densas e compactas, pois esse modelo ofereceria uma otimização da infraestrutura urbana e maior qualidade de vida, o que é explicado principalmente pelo princípio da interação.

Com as premissas constitucionais, somadas às discussões trazidas doutrinariamente sobre a complexidade que envolve o Direito à Cidade, cite-se um instrumento legislativo relevante, o Estatuto da Cidade $^{11}$, o qual oferece princípios que clarificam conflitos ligados à ausência ou inadequação do planejamento do uso do solo.

Por isso, o instrumento de certificação ambiental Selo Casa Azul da Caixa Econômica Federal é estudado neste trabalho a fim de identificar se as premissas por ele traçadas podem influir na implantação de habitações sustentáveis e consequentemente maior qualidade urbana.

\footnotetext{
${ }^{8}$ HARVEY, David. Capítulo 1: Direito à cidade. In Cidades Rebeldes: do direito à cidade à revolução urbana. São Paulo: Martins Fontes, 2014. pp. 27-66.

${ }^{9}$ LEFEBVRE, Henri. Espaço e Política [1972]. Belo Horizonte: UFMG, 2008. p. 82.

${ }^{10}$ REGO, Jaqueline Azevedo de Amorim et al. Cidades Sustentáveis: Lidando com a urbanização de forma ambiental, social e economicamente sustentável. In: Simulação das Nações Unidas para Secundaristas 2013. Disponível em: <http://www.sinus.org.br/2013/wpcontent/uploads/2013/03/17.-PNUMA-Artigo.pdf>. Acesso em 03 jul. 2016. p. 55.

${ }^{11}$ BRASIL. Lei 10.257 de 10 de julho de 2011. Estatuto da Cidade. Disponível em < http://www.planalto.gov.br/ccivil_03/leis/LEIS_2001/L10257.htm>. Acesso em 17 ago. 2017.
} 


\section{POLÍTICA PÚBLICA DE INCENTIVO À HABITAÇÃO SUSTENTÁVEL}

A política pública brasileira no sentido das habitações sustentáveis poderiam estar em grande concretude, de acordo com os princípios constitucionais e com a legislação deles decorrentes. Pelo contexto cronológico, além da Constituição em 1988 ter tratado de matéria urbanística no Brasil em 2001 há o marco importante da promulgação do Estatuto da Cidade.

Porém, mesmo antes desse período, pode-se observar que a forma como o Estado "cria" a cidade é nutrindo-a de elementos financeiros e não por planejamento de políticas de moradia que levem em conta os aspectos sociais.

Este modelo não conseguiu dotar a maior parte da população de condições adequadas de moradia, afinal o mercado formal de urbanização providencia privadamente a "cidade". Atendeu-se as classes médias e altas, e, para os não contemplados restou uma inserção precária no território, longe das oportunidades, mobilidade excludente.

Falando de políticas públicas, cite-se Jaqueline Rego ${ }^{12}$ no entendimento de que o papel da governança na implementação do ambiente sustentável é algo imprescindível.

Por governança compreenda-se a relação de interdependência entre Governo e outros atores não estatais.

José Godinho de Oliveira ${ }^{13}$ indica que, quando da implantação de novos projetos, estes devem ter planos que ao menos possam viabilizar a absorção dos impactos negativos. As precauções hão de visualizar o interesse público. Para ele, não há, efetivamente, políticas territoriais capazes de gerar um ordenamento do território que regule as ações predadoras do capital coorporativo e proponha novas responsabilidades que delineiem possibilidades desenvolvimento social.

Diante deste quadro, é que se passa ao estudo da certificação ambiental em foco neste trabalho a fim de notar, mesmo diante dos obstáculos na execução de políticas públicas para uma implantação de moradias mais sustentáveis e cidades mais acessíveis.

Mesmo que fora dos parâmetros políticos mais tradicionais, esperar-se-ia que incentivo do Governo Federal, através de um produto de Instituição que funciona como seu braço de fomento, a CEF, poderia ser uma forma de interferência positiva nas cidades.

Uma inicial preocupação advinda com os estudos do Selo é que, embora a certificação tenha sido criada em 2010, até o ano de 2017 existem poucas certificações já registradas no país ${ }^{14}$ como a própria CEF informa em seu site.

\footnotetext{
${ }^{12}$ REGO, Jaqueline Azevedo de Amorim et al. Op. Cit.

${ }^{13}$ DE OLIVEIRA, Floriano José Godinho. Território, Estado e Políticas Territoriais: análise das políticas de gestão do território e da recente expansão/reconcentração econômica nos espaços metropolitanos. Scripta Nova. Revista Electrónica de Geografía y Ciencias Sociales, v. 18, 2014. p. 16.

14 ARTHE AZUL: programa: PEC SBPE. Quant. Unidades: 24. Proponente: the. Eng empreendimentos. Local: Teresina/PI. Nível obtido: ouro. BC BELA CINTRA. Programa: PEC SBPE. Quant. Unidades: 112. Proponente: Even Construtora e Incorporadora s/a. Local: São Saulo/SP. Nível obtido: ouro. RESIDENCIAL PEROLA DA PEDRA. Programa: Financiamento Apoio à
} 
A atuação governamental há de estar relacionada ao direito à moradia e habitação, à mobilidade urbana, proteção ao meio ambiente (sonoro, água, solo, ar, fauna e flora), educação, à propriedade, à saúde e ainda outros.

O Estado precisa atuar na reestruturação do Direito à Cidade através de políticas públicas que levem em conta todas essas variáveis, que considere esse espaço como sendo para as pessoas e não apenas como um campo de interesses de capital privado.

$\mathrm{E}$, além dos meios de investimentos diretos imprescindíveis, neste momento há de se refletir sobre o instrumento Selo Casa Azul do agente financeiro ligado ao Governo, a Caixa Econômica Federal.

A financeirização da atividade de expansão imobiliária urbana é praxe inclusive devido a disponibilidade de investimentos ser restrita frente à demanda existente. Tanto para construtores como para compradores é item relevante.

De um lado, o interesse capitalista que assume uma responsabilidade que deveria ser do Estado, qual seja a redução do déficit habitacional, e o faz de acordo com o interesse de lucro. Assim, acessar fundos de menor custo, como os fornecidos para quem consegue o Selo Casa Azul, seria um fator atraente. Já o comprador é desprovido da chance de aquisição de bem imóvel se não for por meio de financiamento.

Essa última circunstância se dá em razão de o direito fundamental à moradia encontrar-se distante de sua efetividade, com a concretização formal se dando apenas para classes econômicas mais abonadas, sendo os mais desfavorecidos relegados à favelização, à precariedade, e à informalidade. Vanilza Andrade ${ }^{15}$ aponta que as unidades do Minha Casa

Produção- recursos SBPE. Quant. Unidades: 80. Proponente: Vita Construtora. Local: bairro Pedra Branca - Palhoça/SC. Nível obtido: ouro. VILLE BARCELONA Programa: Minha Casa Minha Vida - FGTS. Quant. unidades: 32. Proponente: Construtora PRECON. Local: Betim/MG. Nível obtido: Prata. CONDOMÍNIO E /CONDOMINIO G - Paraisópolis. Programa: PAC Urbanização de Favelas. Quant. unidades: 117. Proponente: Prefeitura de São Paulo. Local: São Paulo/SP. Nível obtido: Ouro. EDIFÍCIO HAB2 - CHAPÉU MANGUEIRA/BABILÔNIA. Programa: Pró-Moradia Urbanização de Favelas. Quant. unidades: 16. Proponente: Prefeitura do Rio de Janeiro. Local: Rio de Janeiro/RJ. Ouro. GUARATINGUETÁ. Programa: Minha Casa Minha Vida - FAR. Quant. unidades: 880 Proponente: Construtora Bairro Novo. Local: Santo André/SP. Nível obtido: Ouro. RESIDENCIAL BONELLI. Programa: Imóvel na Planta - SBPE. Quant. unidades: 45. Proponente: Construtora Rogga. Local: Joinville/SC. Nível obtido: Ouro. RESIDENCIAL BRAHMA. Programa: Alocação de Recursos. Quant. unidades: 131. Proponente: Vieira e Moura. Local: Garanhuns/PE. Nível obtido: ouro. RESIDENCIAL PARQUE JEQUITIBÁ. Programa: Financiamento à Produção MPE - recursos SBPE. Quant. unidades: 62. Proponente: Construtora Mazzini. Gomes Local: Vitória/ES. Nível obtido: Ouro. Disponível em <http://www.caixa.gov.br/sustentabilidade/produtos-servicos/selo-casa-azul/Paginas/defaut.a spx>. Acesso em 20 ago. 2017

${ }^{15}$ ANDRADE, Vanilza da Costa. Programa Minha Casa, Minha Vida no contexto da mundialização do capital. Disponível em: <http://www.cbg2014.agb.org.br/resources/anais/1/1404136927_ARQUIVO_C 

O enfoque deste estudo é apreciar em que patamar a certificação ambiental oferecida pela Caixa Econômica Federal poderia influir em implantação de habitações sustentáveis e no Direito à Cidade.

Para conquistar o Selo, o interessado submete-se facultativamente ao cumprimento de regras preestabelecidas de qualidade frente á certificadora para que esta indique o parecer de atendimento ou não dos parâmetros. Trata-se do reconhecimento de um trabalho desenvolvido, o qual, mesmo sem cumprir estritamente as orientações, poderá ser de grande contribuição ambiental, dentro de suas características regionais e culturais. Relevante é a existência de um norte a ser seguido, uma agenda de soluções que confere ganhos de variadas formas.

Dentro do tema de Direito à cidade, urbanismo e construção civil sustentável existem vários Selos. Suely Brasileiro ${ }^{18}$ cita alguns exemplos como a certificação BREEAM (BRE Environmental Assessment Method) criada em 1990, antecipando discussões da Agenda 21 e principal forma de avaliação ambiental de edifícios no Reino Unido. Outro exemplo é o feito pelos EUA, o LEED (Leadership in Energy and Environmental Design) certificação internacional de empreendimentos sustentáveis desenvolvida pelo United States Green Building Council (USGBC). Como certificação internacional cite-se também a AQUA (Alta Qualidade Ambiental), derivada da HQE (Haute Qualité Environnementale).

Tratando agora especificamente do Selo Casa Azul, este envolve desde questões técnicas arquitetônicas à qualidade de vida da comunidade do entorno. Tem como escopo a contribuição do proponente a cidades mais igualitárias, sustentáveis para hoje e para o futuro.

Uma contribuição para as pesquisas foi o chamado "Disco Egan", um estudo realizado na Inglaterra para identificar o que seria necessário fazer para implementar comunidades sustentáveis, a partir de onde se pode mencionar uma orientação dentre as muitas existentes no documento:

Nós recomendamos que o Governo trabalhe com parceiros para fazer uma revisão do plano de metas, com o objetivo de produzir um sistema que reflita o compromisso deste com alta qualidade e pronta tomada de decisão para todos os tipos de aplicações. Propomos ainda que o Governo examine o escopo a fim de atender a soma de interesses nacionais e locais. Quaisquer novos alvos devem refletir os resultados da reengenharia do processo de planejamento. ${ }^{19}$

\footnotetext{
${ }^{18}$ BRASILEIRO, Suely Benevides de Carvalho. Adequação ao Selo Casa Azul da Caixa Econômica Federal de Edificações do Programa Minha Casa Minha Vida. 2013. Dissertação em Engenharia Urbana e Ambiental. Universidade Federal da Paraíba, João Pessoa, 2013. Disponível em < http://tede.biblioteca.ufpb.br/handle/tede/5513>. Acesso em 14 ago. 2017.

${ }^{19}$ OFFICE OF THE DEPUTY PRIME MINISTER ELAND HOUSE. The Egan Review Skills for Sustainable Comunities.. ISBN 1859461425 . London, 2014. Disponível em < http://webarchive.nationalarchives.gov.uk/20070402150321/http://www.communities.gov.uk /pub/264/TheEganReviewSkillsforSustainableCommunities_id1502264.pdf> Acesso em 15 ago. 2017. P. 13. Tradução nossa (We recommend the Government works with partners to undertake
} 


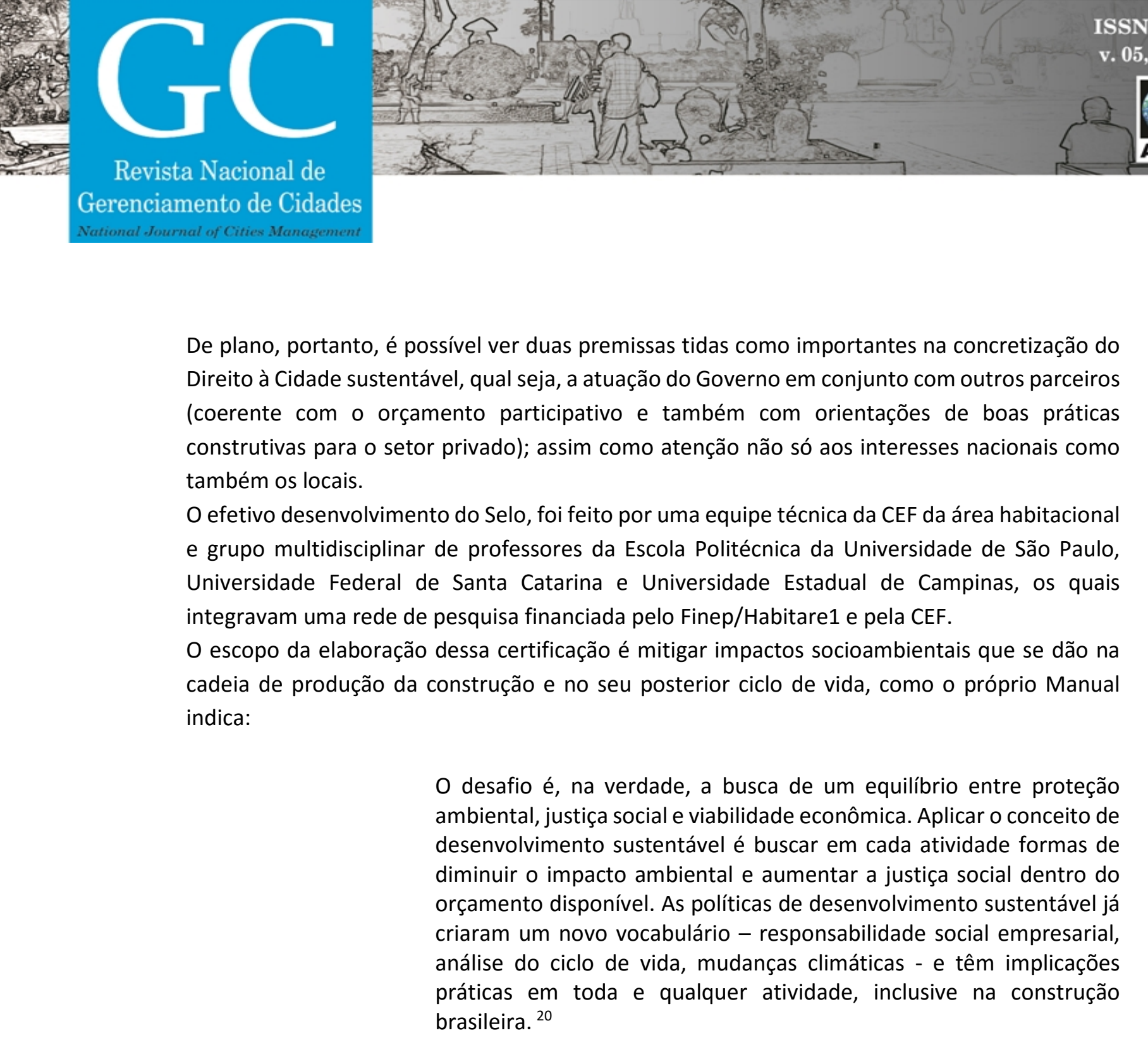

De plano, portanto, é possível ver duas premissas tidas como importantes na concretização do Direito à Cidade sustentável, qual seja, a atuação do Governo em conjunto com outros parceiros de boas práticas construtivas para o setor privado); assim como atenção não só aos interesses nacionais como também os locais.

O efetivo desenvolvimento do Selo, foi feito por uma equipe técnica da CEF da área habitacional e grupo multidisciplinar de professores da Escola Politécnica da Universidade de São Paulo, Universidade Federal de Santa Catarina e Universidade Estadual de Campinas, os quais tegravam uma rede de pesquisa financiada pelo Finep/Habitare1 e pela CEF.

O escopo da elaboração dessa certificação é mitigar impactos socioambientais que se dão na construção e no seu posterior ciclo de vida, como o próprio Manual

O desafio é, na verdade, a busca de um equilíbrio entre proteção ambiental, justiça social e viabilidade econômica. Aplicar o conceito de diminuir o impacto ambiental e aumentar a justiça social dentro do orçamento disponível. As políticas de desenvolvimento sustentável já criaram um novo vocabulário - responsabilidade social empresarial, brasileira. ${ }^{20}$

São necessárias medidas capazes de conferir à cidade um efeito de território digno, com justiça social. O Selo Casa Azul pretende-se colocar como ferramenta para tal objetivo, aplicando-se para construção, uso, manutenção de edificações. Aplica-se a todos os tipos de projetos de empreendimentos habitacionais apresentados à CEF para financiamento ou nos programas de repasse. Podem ser proponentes: empresas construtoras, o Poder Público, cooperativas, associações e entidades representantes de movimentos sociais. O método usado é de verificar se os procedimentos foram feitos.

Como dito, são amplos os aspectos que a CEF coloca para análise, o econômico, o técnico, o social. Enumerando as categorias gerais, tem-se: Qualidade Urbana (categoria 1); Projeto e

a review of existing planning targets, with the aim of producing a system that reflects the Government's commitment to high quality and timely decision making for all types of applications. We propose that the Government should examine the scope for using a combination of national and local targets. Any new targets should reflect the outcomes of planning process re-engineering).

${ }^{20}$ CAIXA. Selo Azul. Boas Práticas para Habitação mais sustentável. Op Cit. p. 11. 



\section{CONCLUSÃO: percorrendo trilhas ao encontro da cidade sustentável}

O Selo Casa Azul é um incentivo às construções sustentáveis, considerando desde o projeto técnico e escolha do terreno; passando pelos meios de eficiência energética e otimização de materiais; e chegando à valorização do entorno, escuta da comunidade e à responsabilidade social.

A partir deste diálogo teórico, a hipótese que se construiu foi de que esse instrumento, oferecendo vantagens financeiras, orientação técnica na agenda do empreendimento e valorizando o pós venda das unidades, fosse capaz de atrair os empreendedores a ele se submeter. E, com isso, haveria amortecimento dos impactos negativos de implantação, incremento de soluções sustentáveis, melhoria de qualidade de vida e, portanto, promoção do Direito à Cidade.

A partir do aprofundamento dos estudos, já com o escopo específico de saber se o Selo poderia ser efetivamente um instrumento financeiro capaz de influir em habitações sustentáveis e ao acesso da sociedade ao Direito à Cidade, a conclusão obtida é de que eficácia tem se demonstrado restrita e limitada.

A forma de atuação dos agentes empreendedores de construções urbanas possui a visão do lucro e isso já houvera sido considerado quando do início das pesquisas. O que se percebeu, porém, é que o modus operandi de obtenção desse retorno de capital permanece em sistema predatório, insustentável inclusive para o próprio interesse de continuidade dos negócios.

Mesmo que as orientações do Selo Casa Azul, com todo o cabedal técnico de soluções oferecidas, seja capaz de baratear o empreendimento, isso não parece ser o suficiente para atrair interessados. Tanto o é, que inclusive as taxas de juros mais atraentes para os proponentes e até para os compradores finais, gerando ciclo virtuoso para as vendas, também é desconsiderado. No Brasil, sequer a cultura de investigação prévia do ambiente urbano existe para se começar o planejamento da obra, mas prepondera o contrário: adaptação do terreno ao projeto já feito.

Mais interessante do que o uso do solo urbano de acordo com sua função social, tem sido empreender em áreas desassistidas de apoio logístico ou infraestrutura, pois os custos ficarão para outros atores: a comunidade que estará nas ilhas suburbanas ou o Estado que aplicará ali recursos públicos.

Apesar de o Selo Casa Azul atribuir a quem o conquista um reconhecimento pelas boas práticas empreendidas; proporcionar ganho de imagem; e melhor gestão do ciclo de vida do produto; vê-se que o número de empreendimentos realizados ainda é pequeno.

As políticas públicas habitacionais e urbanas no país estão ligadas aos interesses de grupos econômicos; inseridas em intricada estrutura, cuja reversão possui complexidade, e um elemento de abrangência quantitativa tão modesta como a certificação sustentável não parece ser capaz de influir com realce. 


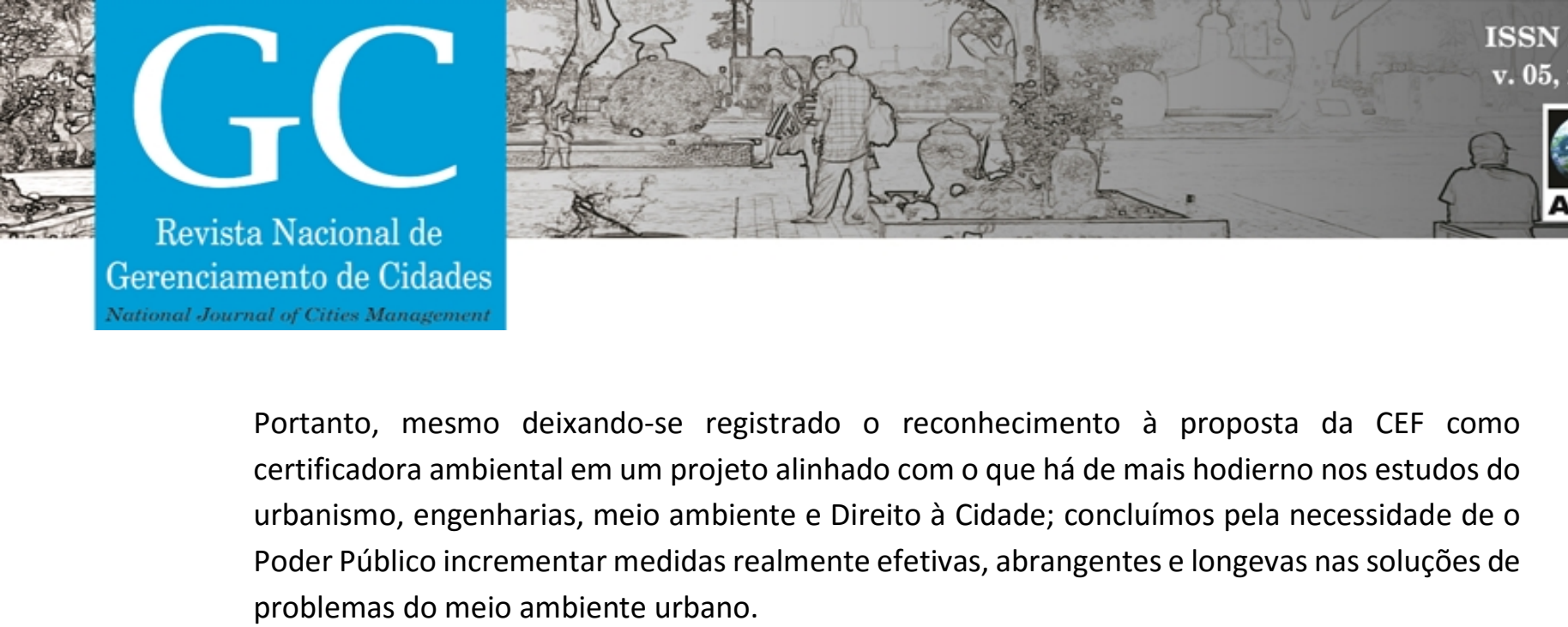


\section{REFERÊNCIAS.}

ANDRADE, Vanilza da Costa. Programa Minha Casa, Minha Vida no contexto da mundialização do capital. Disponivel em: <http://www.cbg2014.agb.org.br/resources/anais/1 /1404136927_ARQUIVO_CBG-VANILZAANDRADE.pdf>. Acesso em: 05 jul. 2016.

BRASIL. Constituição Federal. Publicada em 5 de outubro de 1988. Atualizada até a emenda constitucional número 96 de 6/6/17. Disponível em < http://www.planalto.gov.br/ccivil_03/co nstituicao/constituicaocompilado.htm >. Acesso em 18 ago. 2017.

Lei № 6.766 de 19 de dezembro de 1979. Parcelamento do Solo urbano. Disponível em < http://www.planalto.gov.br/ccivil_03/leis/L6766.htm>. Acesso em 18 ago. 2017.

Lei № 10.257 de 10 de julho de 2011. Estatuto da Cidade. Disponível em < http://www.planalto.gov.br/ccivil_03/leis/LEIS_2001/L10257.htm>. Acesso em 17 ago. 2017

BRASILEIRO, Suely Benevides de Carvalho. Adequação ao Selo Casa Azul da Caixa Econômica Federal de Edificações do Programa Minha Casa Minha Vida. 2013. Dissertação em Engenharia Urbana e Ambiental. Universidade Federal da Paraíba, João Pessoa, 2013. Disponível em < http://tede.biblioteca.ufpb.br/handle/tede/5513>. Acesso em 14 ago. 2017.

CAIXA ECONÔMICA FEDERAL. Selo Azul. Boas Práticas para Habitação mais sustentável. Coordenadores Vanderley Moacyr John, Racine Tadeu Araújo Prado . São Paulo. Páginas \& Letras - Editora e Gráfica, 2010.

Mídias Sustentáveis. Disponível em <http://www.caixa.gov.br/Downloads/midiasustentavel/MS_Selo_Casa_Azul_Nossa_Casa_Nosso_Planeta.pdf>. Acesso em 17 ago. 2017.

Selo Casa Azul. Disponível em <http://www.caixa.gov.br/sustentabilidade/produtosservicos/selo-casa-azul/Paginas/default.aspx>. Acesso em 20 ago. 2017.

DE OLIVEIRA, Floriano José Godinho. Território, Estado e Políticas Territoriais: análise das políticas de gestão do território e da recente expansão/reconcentração econômica nos espaços metropolitanos. Scripta Nova. Revista Electrónica de Geografía y Ciencias Sociales, v. 18, 2014.

HARVEY, David. Capítulo 1: Direito à cidade. In Cidades Rebeldes: do direito à cidade à revolução urbana. São Paulo: Martins Fontes, 2014, pp. 27-66.

LEFEBVRE, Henri. Espaço e Política [1972]. Belo Horizonte: UFMG, 2008.

MARICATO, Ermínia. O Estatuto da cidade periférica. In: O Estatuto da Cidade: Comentado. São Paulo: Ministério das Cidades/Aliança das Cidades, 2010. 
